\title{
Integrating Life Cycle Assessment and Eco-design Strategies for a Sustainable Production of Bio-based Plastics
}

\author{
Venkateshwaran Venkatachalam, Sebastian Spierling, \\ Hans-Josef Endres and Andrea Siebert-Raths
}

\begin{abstract}
In order to design and develop a sustainable bio-based plastic product right from its development phase, it is necessary to analyse and interpret the direct and indirect environmental impacts along the life cycle of the product system through life cycle thinking. Eco-design is a well-established approach in designing products with the consideration and integration of the environmental impacts of the product system, and Life Cycle Assessment (LCA) is a standardized methodology to quantify and analyse the environmental impacts of the product system along the production chain. This paper identifies the practical needs for integrating LCA and eco-design strategies into the production of bio-based plastic products, taking a bio-based computer mouse body made of Poly Lactic Acid (PLA) as a case study.
\end{abstract}

\section{Introduction}

Plastics have an important role in our daily life. From packaging to automotive areas, the use of plastics has steadily increased during the last 100 years and is predicted to keep growing in the future [1]. The major part of the current plastics is based on fossil resources like crude oil. However, in the past few decades, bio-based plastics have become a focus in plastic research [2], due to the finiteness of fossil-based raw materials, renewability of the feedstock used in the bio-based plastics and the current challenges of climate change. Bio-based plastics are defined as ready to use blends, which consist of biopolymers and additives [2]. With increasing bio-based plastic production, the question of whether the bio-based plastics a sustainable alternative to conventional plastics, have been raised repeatedly. Many LCA studies have been conducted for biopolymers [3] but most of these LCA studies are used as a communication tool to show its environmental performance rather than integrated to the design of products manufactured from these

\footnotetext{
V. Venkatachalam $(\bowtie) \cdot$ S. Spierling $\cdot$ H.-J. Endres $\cdot$ A. Siebert-Raths Faculty II-Mechanical Engineering and Bio Process Engineering, Institute for Bioplastics and Biocomposites, University of Applied Sciences and Arts, Hannover, Germany e-mail: venkateshwaran.venkatachalam@hs-hannover.de

(C) The Author(s) 2018

E. Benetto et al. (eds.), Designing Sustainable Technologies,

Products and Policies, https://doi.org/10.1007/978-3-319-66981-6_54
} 
biopolymers. Even though various eco-design studies have been done for the selection of biopolymers [4, 5], very few exist for bio-based plastics. The main objective of this paper is to identify the eco-design strategies for the production of a bio-based plastic material based on its material properties and the results of LCA. To perform this study, an eco-design team was setup, composed of material and process engineers, sustainability experts and marketing representatives. This team analysed the cost, sustainability aspects, chemical and mechanical properties of the different biopolymers and additives before the manufacture of a bio-based plastic product. The cradle to gate LCA has been performed for the product, after the most suitable polymers were chosen. The results of this LCA and its influence on the proposed eco-design strategies will be discussed in this paper.

\section{Description of the Eco-design Process Stages, as Applied to the Case-Study}

\subsection{Motivation Factors}

Benefits and motivation factors [6] for performing product or process eco-design have been analysed as a very first stage, even before LCA and product properties analysis, so that the eco-design team can analyse and identify the strategies within the framework of the product development. The motivation factors not only arise from the manufacturing company but also from external factors such as policies and markets. Some of them are provided here as example:

- Increase the marketability of the bio-based plastic products through product innovation, thereby increasing its demand and reducing costs of raw materials

- Improve the products mechanical and environmental performances by reducing energy and material consumption, having circular economy as a global target,

- Clear communication to the customers and consumers with regards to the products mechanical and environmental performances.

\subsection{Methodology of Eco-design for Bio-based Plastics}

As eco-design process requires to consider a vast array of inter-related aspects such as product economic, technical, ergonomic, market and environmental properties, it requires a multi-disciplinary approach. Based on literature review of eco-design applied to bio-based products [7,8], the different stages considered for the present case study are shown in Fig. 1. It can be seen that the identification and implementation of eco-design strategies is an iterative approach supported by LCA implementation. 
Fig. 1 Methodological stages of eco-design applied to bio-based plastics

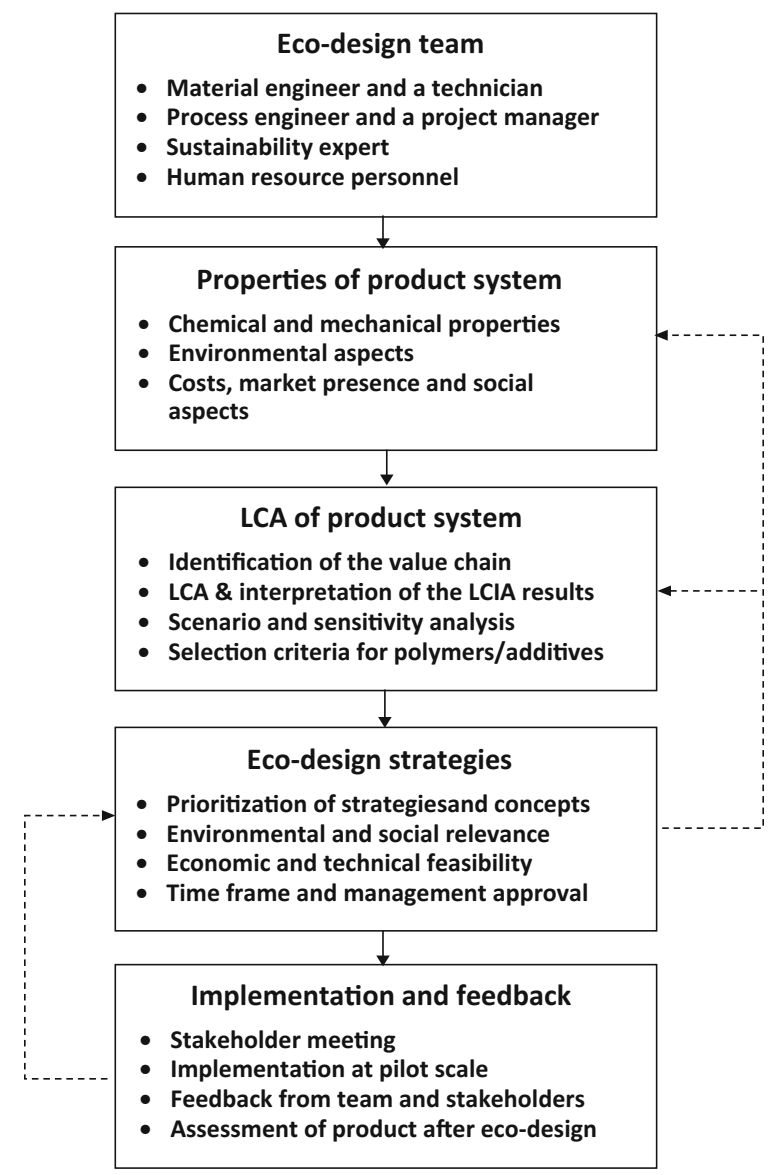

\section{LCA Application}

\subsection{Goal and Scope Definition}

The main goal of this LCA study is to analyse the environmental performance of the product made out of bio-based plastics and then identify opportunities to optimize this product. The results of this LCA study will be helpful to analyse the individual contribution of different processes towards the total environmental impacts. The Life Cycle Impact Assessment (LCIA) results, along with the hot spot and scenario analyses will then be used to develop eco-design strategies for the product. 


\subsubsection{Functional Unit}

The functional unit of the LCA study is the production of $1 \mathrm{~kg}$ of bio-based plastic blend, made primarily of biopolymer PLA, to be used to manufacture 25 pieces of computer mouse bodies, which include right mouse button, left mouse button, palm rest and the base [9].

\subsubsection{System Boundaries}

The system boundaries are set from cradle to gate, which includes raw material acquisition phase, production of the bio-based plastics blends and finally the processing of the blends to manufacture the computer mouse pieces. The use and End of Life (EoL) phases of the product system are not considered for this study due to the limited availability of data on the consumer behaviour and the strategies to use and dispose the products after its use phase. However, some factors influencing these two phases are included as a part of the eco-design strategy definition, which will be explained in Sect. 4. This LCA study is done in accordance to ISO 14040 [10] and ISO 14044 [11] and supported by the software GaBi 6 [12]. From Fig. 2, it can be seen that the raw material acquisition phase includes the manufacture, processing and the transport of the polymers, additives and other chemicals from their original sites to Germany, where they will be extruded, granulated, crystallized and packed as bio-based plastics blends. The main components of the blend are the biopolymers Poly-L-Lactic Acid (PLLA) and Poly-D-Lactic Acid (PDLA), which are produced from sugarcane and sugar beets respectively. Both PLLA and PDLA come under the biopolymer type PLA and is one of the widely used biopolymers with suitable mechanical properties. The processing phase involves in the pre-processing of these bio-based plastic blends before bringing it to a specific form (here, body of the computer mouse) by injection moulding. The finished product is then sent to an assembly site (electronic parts of mouse are not included in the system boundaries) and finally distributed to the consumers. The utilities such as process steam, process water, compressed air and output flows such as emissions and wastes are considered within each process even though they are not explicitly shown in Fig. 2.

\subsubsection{Life Cycle Inventory Data Sources and Data Quality Requirements}

The bio-based plastic blend, which is used in the manufacture of the body of a computer mouse, is made of biopolymers and additives. The production of the bio-based plastic blend takes place in Germany. Inventory data for the manufacture of PLLA, PDLA and other additives in the raw material acquisition phase were picked up from different literature sources [13, 14]. The background Life Cycle Inventory (LCI) datasets were considered for different utilities like process steam, 


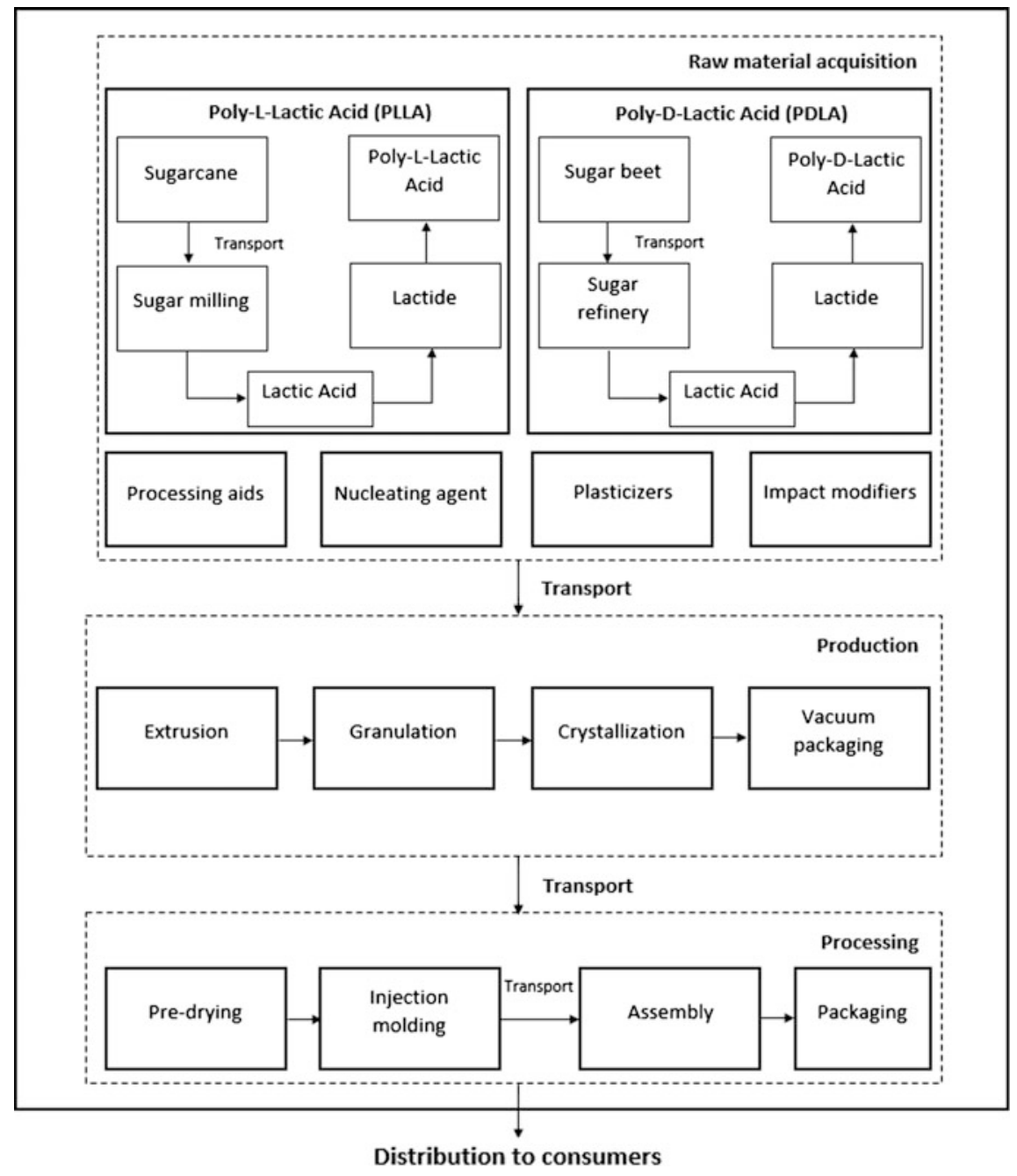

Fig. 2 System boundaries of the product system - computer mouse

natural gas and water, which are involved in the manufacturing of biopolymers and these were selected from GaBi LCI databases. PLLA used in the blend, originally comes from Thailand, whereas PDLA comes from Spain even though both of the raw materials are produced and supplied by the same company. The two polymers along with the additives (from different companies) are then transported to the supplier site and finally to Germany, where they are subjected to extrusion, granulation and crystallization. Primary inventory data were obtained on-site for the production and processing phases, in co-operation with the industrial partners. 
In the case of PLLA and PDLA, we could not obtain the primary inventory data from the polymer manufacturers due to confidentiality issues. However, regional specific secondary datasets are used in the modelling of product system wherever possible, in order to close the data gaps related to the geographical settings. Transoceanic, intra-continental and the local transportation distance of raw materials from the production plant (PLLA and PDLA from Thailand and Spain) to the supplier transformation site (Our institute in Germany where the blends are manufactured with the help of PLLA and PDLA) have been calculated with the help of an online tool EcoTransIT [15], which calculates the distance in accordance to realistic transportation scenarios. The availability and clarity of inventory data is one of the main challenges for this study and is identified as an eco-design strategy in Sect. 4.

\subsection{Impact Assessment and Interpretation}

Different impact assessment methods are available to perform the Life Cycle Impact Assessment (LCIA). The recommendations from the International Reference Life Cycle Data System (ILCD)/Product Environmental Footprint (PEF) were considered for the characterisation of each midpoint impact, and the LCIA results were obtained from the method 'Impacts ILCD/PEF recommendation v1.09' [16] in the $\mathrm{GaBi}$ software. The LCIA results of the study, for the selected impact categories are presented in Table 1.

Global Warming Potential (GWP) presented in Table 1 includes biogenic carbon, as the feedstock comes from renewable resources and biogenic carbon storage during plant growth should be accounted for, in any cradle to gate assessment of

Table 1 Impact assessment results of $1 \mathrm{~kg}$ of bio-based plastic blend, used in the manufacture of computer mouse body

\begin{tabular}{l|l|l}
\hline Impact category (midpoint) & Unit & $\begin{array}{l}\text { Value per functional } \\
\text { unit }\end{array}$ \\
\hline Acidification potential (AP) & Mole $\mathrm{H}^{+}$-eq. & 0.030 \\
\hline Global warming potential (GWP) & $\mathrm{kg} \mathrm{CO}_{2}$-eq. & 1.462 \\
\hline Eutrophication Potential (EP) & Mole N-eq. & 0.099 \\
\hline $\begin{array}{l}\text { Photochemical ozone creation potential } \\
\text { (POCP) }\end{array}$ & $\mathrm{kg} \mathrm{NMVOC}$ & 0.020 \\
\hline Ozone depletion potential (ODP) & kg CFC-11-eq. & $2.933 \mathrm{E}-11$ \\
\hline Abiotic depletion potential (ADP) & kg Sb-eq. & $1.267 \mathrm{E}-04$ \\
\hline Land use (LU) & $\mathrm{kg} \mathrm{C} \mathrm{deficit} \mathrm{eq.}$ & 31.084 \\
\hline Ecotoxicity (ET) & $\mathrm{CTUe}$ & 0.564 \\
\hline Human toxicity (cancer effects) [HT (CE)] & $\mathrm{CTUh}$ & $2.196 \mathrm{E}-08$ \\
\hline Ionizing radiation (IR) & $\mathrm{kBq} \mathrm{U235} \mathrm{eq.}$ & 0.160 \\
\hline Particulate matter (PM) & $\mathrm{kg} \mathrm{PM} \mathrm{2.5-eq.}$ & 0.003 \\
\hline
\end{tabular}




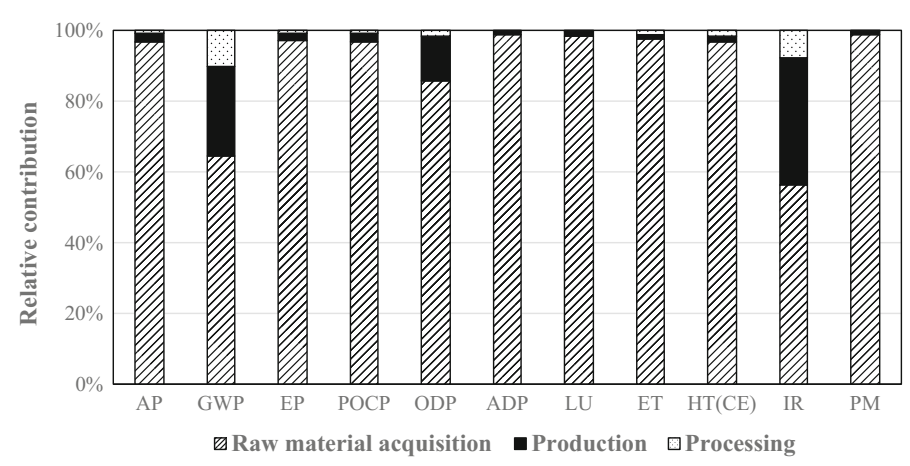

Fig. 3 Relative contribution of life cycle phases (cradle to gate) towards each impact category indicator

bio-based materials [17]. Since use and EoL phases are not considered in this study, it is important to mention that the benefits of accounting for biogenic carbon storage during plant growing is generally counter-balanced with the release of biogenic carbon during use and/or EoL phases. In the results presented here, biogenic carbon storage was accounted for but its release during use and/or EoL not. The relative contribution of each life cycle phase to the different impact categories is shown in Fig. 3 .

It can be found out that the raw material acquisition phase is the most important phase in terms of contribution to all impact categories, contributing to more than $95 \%$ in 8 out of 11 environmental impact categories. For all impact categories, contribution from raw material acquisition phase is mainly induced by the production and transport of PLLA and by the additives required for the production of bio-based plastic blends. Considering GWP impact category, impact from raw material acquisition is mainly due to process steam and power consumption from the production of PLLA. Regarding the production phase, the power consumption and compressed air used for different production processes contribute mainly to the impact on GWP (25.5\%). Finally, contribution from processing phase to the GWP $(10 \%)$ comes from the power consumption for the injection moulding of the plastic blends and the transportation of the finished products to the final assembly. Even though the contribution of the production phase to the impact on ODP (12.6\%) and the processing phase (1.4\%) mainly comes from the power consumption, in the case of raw material acquisition phase (86\%), major contribution comes from the impact modifiers (fossil-based acrylic additives used to improve the product impact strength, one of its mechanical properties) and the polymer (PLLA). IR follows the same tendency as that of ODP, with the contribution in raw material acquisition $(56.3 \%)$ coming from the polymer (PLLA) manufacture, for the production (36.1\%) and processing $(7.5 \%)$, contribution coming from the power consumption. Some of the eco-design strategies are identified based on the interpretation of the LCIA results. 


\subsection{Scenario Analysis}

Scenario analysis is a method, where boundary conditions (i.e. type of process and associated quantity) of some of the key process parameters are modified in the inventory, in order to analyse the variation induced on LCIA results. Scenario analysis can be a powerful method to identify different potential strategies supporting the optimisation of product's environmental performance.

The LCIA results highlighted that a significant amount of environmental impacts comes from the transoceanic transportation of the polymer PLLA i.e. the transportation of polymer from Thailand, where it was originally manufactured, to Germany, where it will be used in the manufacture of bio-based plastic product. In the scenario analysis, the trans-oceanic cargo transportation of PLLA is kept as a base scenario, compared to a scenario of cargo transportation of PLLA from Spain, and another scenario of truck transportation of PLLA from Spain. These scenarios appeared as feasible since the same company supply PLLA from Thailand and PDLA from Spain. Although there was no significant change in most of the impact categories, the change in the most significant impact categories AP, GWP, EP and POCP for the two scenarios is shown alongside the base scenario in Fig. 4. At least $21 \%$ reduction is observed in the total impact on AP when the PLLA is produced and transported by truck from Spain to Netherlands when compared to the base scenario.

Additives are also used in the manufacture of bio-based plastic product in order to increase and optimize the mechanical properties of the product. One such additive is the impact modifiers, which are used for increasing flexibility and impact strength to meet physical property requirements of rigid parts [18]. These modifiers are mostly fossil-based acrylic compounds and production of these modifiers contributes to a significant amount of environmental impacts. A new variant of bio-based impact modifiers has been developed and is already available on the market [19]; however, the scale of its production is much smaller compared to the already established conventional impact modifiers. These bio-based impact modifiers are Polyhydroxyalkanoate (PHA) based, used in the polymer blends to improve the mechanical properties of PLA [19]. A scenario analysis was performed

Fig. 4 Scenario analysis for the transportation of PLLA from Thailand to Europe

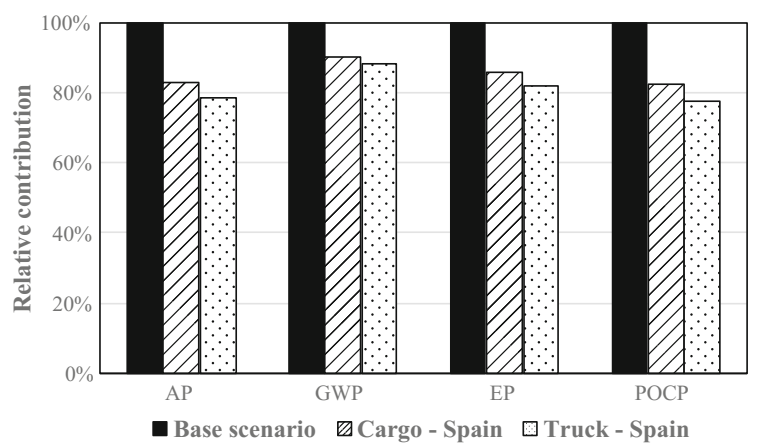


with the replacement of the fossil-based impact modifiers by PHA based additives. Eco-design strategies were identified based on these scenario analyses.

\section{Identification of Eco-design Strategies}

From the LCIA results and scenario analysis, considered together with costs and materials properties, eco-design strategies have been proposed and some of the important strategies are listed in Table 2, taking into account the different aspects involved in the product development. Environmental impacts, economic and technical feasibility are scored arbitrarily on a scale going from 1 to 5 defined by the eco-design team and stakeholders, with 1 being least feasible (for economic and technical feasibility) or least relevant (for environmental improvement) and 5 being highly feasible and highly relevant. A 'Time frame', ranging from Short Term (ST), Medium Term (MT) and Long Term (LT) is also set, for the likelihood of implementing these strategies, based on the previously existing manuals on eco-design such as 'Practical Manual of Ecodesign. Implementation in 7 steps' [6], 'Design for Sustainability - A practical approach for developing economies' [20] and 'Product Design and Life Cycle Assessment' [21]. The first two strategies presented in Table 2 are based on the results of scenario analysis and the related environmental performances. Therefore, it is required that inventory data considered for polymers and additives must be transparent and representative, allowing to perform a comprehensive LCA and to communicate the LCIA results based on a consistent model, which will also affect the material development. Improving the mechanical, ergonomic, recycling and biodegradable properties of the product not only have a high environmental relevance but also helpful to position bio-based plastic products as a sustainable option in a long term. The implemented strategies must be reviewed among the team and stakeholders continuously, as there is always a potential for improvement.

Table 2 Proposed eco-design strategies after analysing different aspects of the bio-based computer mouse body

\begin{tabular}{l|l|l|l|l}
\hline Strategies & $\begin{array}{l}\text { Environmental } \\
\text { improvement }\end{array}$ & $\begin{array}{l}\text { Economic } \\
\text { feasibility }\end{array}$ & $\begin{array}{l}\text { Technical } \\
\text { feasibility }\end{array}$ & $\begin{array}{l}\text { Time } \\
\text { frame }\end{array}$ \\
\hline $\begin{array}{l}\text { Sourcing of polymers } \\
\text { from Europe }\end{array}$ & 4 & 2 & 5 & LT \\
\hline Bio-based additives & 3 & 2 & 3 & MT \\
\hline Clarity in inventory data & 2 & 5 & 4 & ST \\
\hline $\begin{array}{l}\text { Mechanical properties of } \\
\text { the polymers }\end{array}$ & 3 & 2 & 2 & MT \\
\hline $\begin{array}{l}\text { Ergonomics of the } \\
\text { product }\end{array}$ & 4 & 2 & 2 & MT \\
\hline Recyclability & 5 & 1 & 4 & MT \\
\hline Biodegradability & 3 & 3 & 2 & MT \\
\hline
\end{tabular}




\section{Conclusion}

LCA of a bio-based computer mouse body was conducted on a cradle to gate basis. It was found out that the raw material acquisition phase constitutes the major share in all of the environmental impacts. Several strategies for an eco-design of a bio-based product were identified based on the LCIA results, scenario analyses and consideration of some alternative aspects of the product. Some of the methodological and practical requirements for implementing eco-design strategies at the level of bio-based plastics manufacturing were also shown. Once implemented these strategies should pave the way for a sustainable production of bio-based plastics.

Acknowledgements The authors would like to thank the German Federal Ministry of Education and Research as well as the German Federal Ministry of Food and Agriculture for the funding and support to the research project in which this study has been conducted.

\section{References}

1. http://www.plasticseurope.org/documents/document/20161014113313-plastics_the_facts_ 2016_final_version.pdf, (Accessed 10.06.2017).

2. Endres H-J, Siebert-Raths A, Engineering Biopolymers Markets, Manufacturing, Properties and Applications, Carl Hanser Verlag GmbH \& Co. KG, 2011.

3. Yates M, Barlow C.Y, Life Cycle Assessments of biodegradable, commercial biopolymers A critical review, Resources Conservation and Recycling, Vol. 78, 2013, pp. 54-66.

4. Olwill J.A., Wright E.I, Rahimifard S, A holistic approach to design support for bio-polymer based packaging. Journal of Polymers and the Environment, 20, 2012, pp. 1112-1123.

5. Ribeiro I, Peças P, Henriques E, A life cycle framework to support materials selection for Ecodesign: A case study on biodegradable polymers, Materials \& Design, Vol. 51, 2013, pp. 300-308.

6. IHOBE S.A, Manual Práctico de Ecodiseño-Operativa de implantación en 7 pasos, Sociedad pública de gestión ambiental, 2001.

7. González-García S, Silva F.J, Moreira M.T, Castilla Pascual R, García Lozano R, Gabarrell X, Rieradevall Pons J, Feijoo G, Combined application of LCA and eco-design for the sustainable production of wood boxes for wine bottles storage, International Journal of Life Cycle Assessment, Vol. 16, 2011, pp. 224-237.

8. Muñoz I, Gazulla C, Bala A, Puig R, Fullana P, LCA and ecodesign in the toy industry: case study of a teddy bear incorporating electric and electronic components, International Journal of Life Cycle Assessment, Vol. 14, 2009, pp. 64-72.

9. https://www.nager-it.de/maus, (Accessed 05.03.2017).

10. ISO 14040:2006 Environmental management-life cycle assessment-principles and framework.

11. ISO 14044:2006 Environmental management-life cycle assessment-requirements and guidelines.

12. GaBi, Thinkstep AG; LBP-GaBi, University of Stuttgart: GaBi Software System, Leinfelden-Echterdingen/Germany, 2013.

13. Groot W.J, Boren T, Life cycle assessment of the manufacture of lactide and PLA biopolymers from sugarcane in Thailand, International Journal of Life Cycle Assessment, Vol. 15, No. 9, 2010, pp. 970-984. 
14. Harbec A, Lactic acid production from agribusiness waste starch fermentation with Lactobacillus Amylophilus and its cradle-to-gate life cycle assessment as a precursor to Poly-L-Lactide, 2010.

15. http://www.ecotransit.org/index.de.html, (Accessed 12.03.2017).

16. http://eplca.jrc.ec.europa.eu/uploads/ILCD-Recommendation-of-methods-for-LCIA-def.pdf, (Accessed 15.04.2017).

17. Pawelzik P, Carus M, Hotchkiss J, Narayan R, Selke S, Wellisch M, Weiss M, Wicke B, Patel M, Critical aspects in the LCA of bio-based materials-Reviewing methodologies and deriving recommendations, Resources, Conservation and Recycling, Vol. 73, 2013, pp. 211-228.

18. Impact modifiers: How to make your compound tougher https://www.pharosproject.net/ uploads/files/sources/1828/1359960957.pdf, (Accessed 09.01.2018).

19. http://www.yield10bio.com/sites/default/files/ANTEC-PLA_PVC.pdf, (Accessed 16.05.2017).

20. Design for Sustainability -A practical approach for developing economies http://www.d4sde.org/manual/d4stotalmanual.pdf, (Accessed 12.05.2017).

21. Zbicinski I, Stavenuiter J, Kozlowska B, van de Coevering H.P.M., Product Design and Life Cycle Assessment, The Baltic University Press, 2006.

Open Access This chapter is licensed under the terms of the Creative Commons Attribution 4.0 International License (http://creativecommons.org/licenses/by/4.0/), which permits use, sharing, adaptation, distribution and reproduction in any medium or format, as long as you give appropriate credit to the original author(s) and the source, provide a link to the Creative Commons license and indicate if changes were made.

The images or other third party material in this chapter are included in the chapter's Creative Commons license, unless indicated otherwise in a credit line to the material. If material is not included in the chapter's Creative Commons license and your intended use is not permitted by statutory regulation or exceeds the permitted use, you will need to obtain permission directly from the copyright holder.

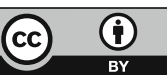

